\title{
Reguladores de crescimento vegetal no cultivo in vitro de Mentha $x$ Piperita L.
}

MORAIS, T.P. ${ }^{1 ;}$ ASMAR, S.A. ${ }^{*}$; LUZ, J.M.Q.1

'Universidade Federal de Uberlândia - UFU, Instituto de Ciências Agrárias, Campus Umuarama, Av. Amazonas s/n, CEP 38400-902, Uberlândia - MG, Brasil, fone (34) 3218-2283. *siasmar@yahoo.com.br

RESUMO: A micropropagação é uma técnica muitas vezes indicada para a multiplicação em larga escala de plantas com propriedades medicinais. Dentre elas, destaca-se a hortelã-pimenta (Mentha x Piperita L.), cujo óleo essencial é utilizado no tratamento de transtornos digestivos e respiratórios. Para otimizar o protocolo de micropropagação dessa espécie são necessários estudos, principalmente quanto à suplementação do meio de cultura para garantir a produção massal in vitro e posterior extração do óleo essencial. Nesse contexto, objetivou-se avaliar o efeito de concentrações e combinações de reguladores de crescimento vegetal na morfogênese in vitro de hortelã-pimenta. Segmentos nodais provenientes de plântulas estabelecidas in vitro foram utilizados como fonte de explante e inoculados em meio de cultura MS suplementado com 0; 2,0 e 4,0 mg L-1 de BAP (6-benzilaminopurina), 0; 0,5 e 1,5 $\mathrm{mg} \mathrm{L}^{-1}$ de ANA (ácido naftalenoacético) e $0 ; 0,5$ e $1,0 \mathrm{mg} \mathrm{L}^{-1}$ de $\mathrm{GA}_{3}$ (ácido giberélico). $O$ delineamento experimental adotado foi inteiramente casualizado, com os tratamentos distribuídos em esquema fatorial $3 \times 3 \times 3 \mathrm{com}$ oito repetições. Concluiu-se que o BAP favoreceu a sobrevivência de segmentos nodais de $M$. $x$ Piperita inoculados in vitro e, quando combinado ao $\mathrm{GA}_{3}$, promoveu a brotação dos explantes. Essas características, no entanto, não foram estimuladas pela adição de ANA ao meio de cultura. Conclui-se que após a multiplicação dos brotos in vitro estes devem ser transferidos para meio sem reguladores para seu desenvolvimento. Apesar dos efeitos benéficos do BAP na organogênese de $M$. x Piperita, elevadas concentrações deste regulador de crescimento vegetal promoveram a formação de calos.

Palavras-chave: hortelã-pimenta, cultura de tecidos, giberelina, auxina, citocinina

ABSTRACT:Plant growth regulators on in vitro culture of Mentha $x$ piperita L. Micropropagation is a technique used for the large-scale production of medicinal plants. Among them, peppermint (Mentha $x$ piperita L.) may be mentioned because of the pharmacological importance of its essential oil, which is used on the treatment of digestive and respiratory disorders. Studies are needed in order to optimize the micropropagation protocol of this species, especially concerning the culture medium, to ensure the in vitro mass clonal production and to enable the future extraction of the plant essential oil. Therefore, this work aimed to evaluate the effects of concentrations and combinations of different plant growth regulators on the in vitro morphogenesis of peppermint. Nodal segments from plantlets already established in vitro were used as explants and inoculated on MS medium supplemented with $0,2.0$ and $4.0 \mathrm{mg} \mathrm{L}^{-1}$ of BAP (6-benzylaminopurine), $0,0.5$ and $1.5 \mathrm{mg} \mathrm{L}^{-1}$ of NAA (naphthalene acetic acid) and 0; 0.5 and $1.0 \mathrm{mg} \mathrm{L}^{-1}$ of $\mathrm{GA}_{3}$ (gibberellic acid). The experiment was in a completely randomized design, set up as a $3 \times 3 \times 3$ factorial design with eight replicates. We concluded that BAP increases the survival rate of in vitro inoculated nodal segments of $M . x$ piperita. In addition, its combination with $\mathrm{GA}_{3}$ stimulates explants shooting. Those aspects, however, are not promoted by the addition of NAA into the culture medium. Also, the results indicate that, after in vitro multiplication, peppermint shoots must be transferred to another medium without plant growth regulators for shoot elongation. High concentrations of BAP promote calli induction, despite having beneficial effects on the organogenesis of $M$. piperita.

Keywords: peppermint, tissue culture, gibberellin, auxin, cytokinin

\section{INTRODUÇÃO}

Apesar dos avanços observados na medicina moderna, as plantas medicinais ainda

desempenham importante papel na saúde mundial. Seu uso aumentou expressivamente nas duas

Recebido para publicação em 04/04/2013

Aceito para publicação em 14/01/2014

10.1590/1983-084X/13_017

Rev. Bras. PI. Med., Campinas, v.16, n.2, supl. I, p.350-355, 2014. 
últimas décadas (Who, 2009), sendo que cerca de $30 \%$ de todas as substâncias avaliadas como agentes terapêuticos são derivados de produtos naturais (Calixto, 2005; Veiga-Junior \& Mello, 2008).

O gênero Mentha inclui plantas e ervas aromáticas perenes, cultivadas por seus óleos essenciais, os quais são empregados tanto para fins medicinais como culinários (Cardoso et al., 2000; Corrêa et al., 2003; Héctor et al., 2005; Lorenzi \& Matos, 2008). A composição química desses óleos varia de planta para planta e em função de fatores abióticos (Souza, 2006).

Uma espécie que se destaca no gênero Mentha por suas propriedades medicinais é a hortelã-pimenta (Mentha x piperitaL., Lamiaceae), que pode ser empregada no tratamento de náuseas, cólicas gastrointestinais, flatulências, cálculos biliares, icterícia, ansiedade, e expectoração (Lorenzi \& Matos, 2008). Estudos de seu óleo essencial demonstram que este é rico em mentona (14 a 32\%) e mentol (30 a 50\%) (Cardoso et al., 2000). Sua propagação pode ocorrer via sexuada ou vegetativamente. No entanto, as plantas propagadas por sementes são heterogêneas, o que dificulta seu uso para propósitos farmacêuticos devido à variabilidade genética e bioquímica (Vieira, 2009). Por outro lado, a multiplicação por estaquia ou divisão de touceira pode permitir o acúmulo de vários fungos sistêmicos, bactérias e infecções virais que comprometem a propagação vegetativa (Goleniowski et al., 2003) e a produção de óleo essencial.

Devido à importância do óleo de Mentha $x$ piperita, sua extração por meio de plantas micropropagadas é uma das alternativas que pode ser viável na obtenção rápida deste produto. Vários estudos in vitro têm sido conduzidos com o gênero Mentha, obtendo protocolos de alta eficiência para cultura de células, calos, e regeneração de brotos a partir de gemas axilares e explantes foliares (Lin \& Staba, 1961; Cellarova, 1992; Shasany et al., 1998; Ghanti et al., 2004; Sunandakumari et al., 2004; Lucchesini et al., 2006; Lima et al., 2007; Raja \& Arockiasamy, 2008; Asmar et al., 2011).

Partindo do pressuposto de que o sucesso do cultivo in vitro de espécies vegetais depende de fatores associados à indução e ao controle da morfogênese quanto à regeneração de brotos e raízes no processo de organogênese, torna-se imprescindível o controle da composição do meio de cultura. Nesse escopo, diversas classes de reguladores vegetais têm sido empregadas nas técnicas de cultura de tecidos, com ênfase na suplementação do meio com auxinas e citocininas. Recentemente, também tem sido proposta a atuação decisiva das giberelinas em muitos aspectos do desenvolvimento das plantas (Souza et al., 2010).
O ácido giberélico $\left(\mathrm{GA}_{3}\right)$ é, entre as giberelinas, um dos mais usados para manipular o crescimento vegetal, por estimular a expansão e divisão celular (Weiss \& Ori, 2007; Morgante \& Lombardi, 2004). Desta forma, supõe-se sua interação com os demais reguladores vegetais.

Assim, este trabalho teve como objetivo avaliar o efeito de concentrações e combinações dos reguladores de crescimento vegetal 6-benzilaminopurina (BAP), ácido naftaleno-acético (ANA) e ácido giberélico $\left(\mathrm{GA}_{3}\right)$ na morfogênese in vitro de hortelã-pimenta.

\section{MATERIAL E MÉTODOS}

O experimento foi conduzido no laboratório de Biotecnologia Vegetal do Instituto de Ciências Agrárias da Universidade Federal de Uberlândia. Para o estabelecimento in vitro da hortelã-pimenta, foi realizada a desinfestação de brotações novas (coletadas na Fazenda Experimental do Glória $18^{\circ} 57^{\prime} 30^{\prime \prime S}$ e $48^{\circ} 12^{\prime} 00^{\prime \prime} \mathrm{W}$ ) em imersão em água corrente durante uma hora. Após este período, foi realizada nova imersão em solução de álcool etílico 50\% ( $\left.\mathrm{v} \mathrm{V}^{-1}\right)$ durante um minuto, seguida da imersão em solução de hipoclorito de sódio $1,5 \%$ com duas gotas de Tween 20 por $100 \mathrm{~mL}$ de solução durante 15 minutos. Posteriormente, as brotações foram lavadas três vezes com água destilada e autoclavada e inoculadas em frascos contendo 30 $\mathrm{mL}$ de meio de cultura MS (Murashige \& Skoog, 1962) e $30 \mathrm{~g} \mathrm{~L}^{-1}$ de sacarose, $7 \mathrm{~g} \mathrm{~L}^{-1}$ de ágar e $\mathrm{pH}$ ajustado em 5,8 antes da autoclavagem $\left(121^{\circ} \mathrm{C}\right.$ e 1 atm por 20 minutos).

Após 60 dias, segmentos nodais oriundos do estabelecimento in vitro foram inoculados em meio MS contendo diferentes concentrações e combinações de reguladores de crescimento. O experimento foi conduzido em delineamento experimental inteiramente casualizado. As combinações entre as doses dos reguladores de crescimento vegetal resultaram em um fatorial $3 \times 3 \times 3$, totalizando 27 tratamentos. As concentrações utilizadas foram: $0 ; 2,0$ e $4,0 \mathrm{mg} \mathrm{L}^{-1}$ de BAP (6-benzilaminopurina), 0; 0,5 e 1,5 $\mathrm{mg} \mathrm{L}^{-1}$ de ANA (ácido naftaleno-acético) e 0; 0,5 e 1,0 $\mathrm{mg} \mathrm{L}^{-1} \mathrm{de} \mathrm{GA}_{3}$ (ácido giberélico). Cada parcela foi constituída por dois frascos contendo dois explantes cada, e cada tratamento representado por oito repetições. Todos os frascos foram mantidos em sala de crescimento nas condições de iluminação artificial fornecida por lâmpadas fluorescentes do tipo "branca fria", com irradiância de $40 \mathrm{mols} \mathrm{m}^{-2} \mathrm{~s}^{-1}, 16$ horas de fotoperíodo e temperatura de $26 \pm 2^{\circ} \mathrm{C}$.

Ao final de 45 dias o material foi avaliado quanto ao percentual de sobrevivência (número de explantes desenvolvidos por número de explantes

Rev. Bras. PI. Med., Campinas, v.16, n.2, supl. I, p.350-355, 2014. 
inoculados) (\%), número de brotos por explante, comprimento dos brotos $(\mathrm{cm})$ e calogênese $(\%)$. Para todas as características, o teste $F$ da análise de variância foi aplicado, seguido pelo teste de Tukey para comparações entre reguladores vegetais, ambos a 0,05 de significância.

\section{RESULTADO E DISCUSSÃO}

Não houve interação tripla para as características avaliadas, ou seja, não houve interação entre as doses de BAP, de ANA e de $\mathrm{GA}_{3}$. A sobrevivência dos explantes, o comprimento médio dos brotos e o percentual de calos formados foram influenciados pelas doses de BAP combinadas às doses de ANA e de BAP com $\mathrm{GA}_{3}$. O número de brotos por explante, por sua vez, dependeu das interações duplas entre $\mathrm{GA}_{3}$ e ANA e entre $\mathrm{GA}_{3} \mathrm{e}$ BAP (Tabela 1).

A auxina (ANA) foi antagônica à citocinina (BAP) quanto à sobrevivência dos explantes inoculados, exceto em concentrações mais elevadas desta citocinina, nas quais, provavelmente, prevaleceu seu efeito regulatório. De maneira geral, o BAP aumentou o percentual de sobrevivência dos explantes de hortelã-pimenta inoculados in vitro, principalmente na concentração de $4 \mathrm{mg} \mathrm{L}^{-1}$, independente das doses de ANA e $\mathrm{GA}_{3}$ (Tabela 2), configurando percentuais que variaram de 71,43 a $91,67 \%$ de sobrevivência. Isto ocorre uma vez que a citocinina controla a expressão de genes envolvidos na senescência de tecidos e órgãos vegetais, inibindo-os ou retardando os efeitos fisiológicos degenerativos, o que implica no aumento da longevidade celular (Morgante \& Lombardi, 2004).

Observaram-se maiores médias de número de brotos com a elevação da concentração de BAP associado ao uso de $\mathrm{GA}_{3}$ (até 6,08 brotos/explante na combinação de $4 \mathrm{mg} \mathrm{L}^{-1}$ de BAP e $0,5 \mathrm{mg} \mathrm{L}^{-1}$ de $\mathrm{GA}_{3}$ ). Em contrapartida, ANA combinado à giberelina não foi favorável à formação de brotos (Tabela 3). Resultado semelhante foi obtido por Brum et al. (2002) estudando a micropropagação da figueira (Ficuscarica L.). Estes autores verificaram que o aumento da concentração de ANA reduziu o número de brotos.

Assim, observou-se que a auxina testada prejudicou a sobrevivência dos explantes inoculados e inibiu a brotação de hortelã-pimenta in vitro. Além disso, o BAP estimulou a formação de parte aérea, o que corrobora a literatura referente a experimentos com espécies do gênero Mentha (Ghanti et al., 2004; Lucchesini et al., 2006; Raja \& Arockiasamy, 2008) e, neste caso, pode ser sugerido um sinergismo entre esta citocinina e o ácido giberélico, indicando que $\circ \mathrm{GA}_{3}$ pode estimular a multibrotação quando combinado ao BAP.

$\mathrm{Na}$ ausência da citocinina, ANA e $\mathrm{GA}_{3}$ reduziram a altura dos brotos formados, assim como a aplicação isolada de BAP (na ausência da auxina e da giberelina). A suplementação do meio de cultura com $1,0 \mathrm{mg} \mathrm{L}^{-1}$ de $\mathrm{GA}_{3}$ e BAP também resultou na formação de brotos menores, principalmente na maior dose de BAP aplicada (4 mg L-1), configurando redução de $61 \%$ no comprimento médio dos brotos comparado à mesma dose de $\mathrm{GA}_{3}$ na ausência da citocinina (Tabela 4).

Skala \& Wysokinska (2004) e Garlet et al. (2011) também observaram redução no alongamento de plantas de Salvia nemorosa L. e de Mentha gracilis Sole, respectivamente, durante a proliferação in vitro destas espécies com o aumento da concentração de BAP. Esses resultados são consistentes com a afirmação de Pasqual (2001), que relata que elevadas concentrações de citocininas podem reduzir o tamanho das brotações no cultivo in vitro.

É interessante notar que maiores comprimentos de brotos, por sua vez, foram obtidos em meio de cultura sem suplementação

TABELA 1. Resumo da análise de variância dos dados de sobrevivência, número e comprimento de brotos, e da formação de calos em explantes de hortelã-pimenta em função das concentrações e combinações de reguladores vegetais.

\begin{tabular}{|c|c|c|c|c|c|}
\hline \multirow{2}{*}{ FV } & \multirow{2}{*}{ GL } & \multicolumn{4}{|c|}{ Quadrado médio } \\
\hline & & Sobrevivência & Número de brotos & Comprimento & Calogênese \\
\hline Doses de BAP & 2 & $4,415^{\circ}$ & 143,568 & 8,911 & $9,047^{\circ}$ \\
\hline Doses de ANA & 2 & $7,754^{\circ}$ & $279,893^{*}$ & $19,218^{*}$ & $9,665^{*}$ \\
\hline Doses de $\mathrm{GA}_{3}$ & 2 & $0,892^{\text {ns }}$ & $50,255^{*}$ & $0,888^{\text {ns }}$ & 0,428 \\
\hline Doses BAP*ANA & 4 & $2,032^{\circ}$ & $8,469^{\text {ns }}$ & $9,944^{*}$ & 9,682 \\
\hline Doses $\mathrm{BAP}^{*} \mathrm{GA}_{3}$ & 4 & $2,139^{\circ}$ & $20,000^{*}$ & $1,577^{\circ}$ & $0,478^{\circ}$ \\
\hline Doses $\mathrm{ANA}^{*} \mathrm{GA}_{3}$ & 4 & $0,604^{\text {ns }}$ & $13,853^{\circ}$ & $0,780^{\text {ns }}$ & $0,164^{\text {ns }}$ \\
\hline Doses $\mathrm{BAP}^{*} \mathrm{ANA}^{*} \mathrm{GA}_{3}$ & 8 & $0,344^{\text {ns }}$ & $2,036^{\text {ns }}$ & $0,377^{\text {ns }}$ & $0,178^{\text {ns }}$ \\
\hline Resíduo & 179 & 0,332 & 4,679 & 0,395 & 0,129 \\
\hline
\end{tabular}

'e ns: significativo e não significativo, respectivamente, a $5 \%$ pelo teste $F$. 
TABELA 2. Percentual de sobrevivência (\%) de explantes de hortelã-pimenta em função das concentrações dos reguladores vegetais $\mathrm{BAP}, \mathrm{ANA}$ e $\mathrm{GA}_{3}$ combinados'

\begin{tabular}{llll}
\hline & BAP $(\mathbf{m g ~ L}-1)$ & \\
\cline { 2 - 4 } ANA $\left(\mathbf{m g ~ L}^{-1}\right)$ & 0,0 & 2,0 & 4,0 \\
\hline 0,0 & $95,83 \mathrm{aA}$ & $93,75 \mathrm{aA}$ & $88,09 \mathrm{aA}$ \\
0,5 & $52,17 \mathrm{~b} \mathrm{~B}$ & $70,83 \mathrm{~b} \mathrm{AB}$ & $85,42 \mathrm{aA}$ \\
1,5 & $33,33 \mathrm{~b} \mathrm{~B}$ & $67,50 \mathrm{~b} \mathrm{~A}$ & $81,82 \mathrm{aA}$ \\
\hline $\mathbf{G A}_{3}\left(\mathbf{m g ~ L}^{-1}\right)$ & & $\mathrm{BAP}\left(\mathrm{mg} \mathrm{L}^{-1}\right)$ & \\
\hline 0,0 & $76,09 \mathrm{aA}$ & $64,58 \mathrm{~b} \mathrm{~A}$ & $71,43 \mathrm{aA}$ \\
0,5 & $45,83 \mathrm{~b} \mathrm{~B}$ & $77,27 \mathrm{ab} \mathrm{A}$ & $91,67 \mathrm{aA}$ \\
1,0 & $60,42 \mathrm{ab} \mathrm{B}$ & $93,18 \mathrm{aA}$ & $90,91 \mathrm{aA}$ \\
\hline
\end{tabular}

${ }^{1}$ Médias seguidas por letras distintas, minúsculas na coluna e maiúsculas na linha dentro de $A N A$ e dentro de $\mathrm{GA}_{3}$, diferem entre si pelo teste de Tukey a 0,05 de significância.

TABELA 3. Número médio de brotos de hortelã-pimenta em função das concentrações dos reguladores vegetais BAP, ANA e GA $_{3}$ combinados ${ }^{1}$.

\begin{tabular}{llll}
\hline & $\mathbf{G A}_{3}\left(\mathbf{m g ~ L}^{-1}\right)$ & \\
\cline { 2 - 4 } $\mathbf{B A P}\left(\mathbf{m g ~ L}^{-1}\right)$ & 0,0 & 0,5 & 1,0 \\
\hline 0,0 & $1,87 \mathrm{aA}$ & $1,67 \mathrm{c} \mathrm{A}$ & $1,96 \mathrm{~b} \mathrm{~A}$ \\
2,0 & $1,79 \mathrm{a} \mathrm{B}$ & $3,50 \mathrm{~b} \mathrm{~A}$ & $4,36 \mathrm{aA}$ \\
4,0 & $3,09 \mathrm{a} \mathrm{B}$ & $6,08 \mathrm{aA}$ & $4,77 \mathrm{aA}$ \\
\hline ANA $\left(\mathbf{m g ~ L}^{-1}\right)$ & & $\mathrm{GA}_{3}\left(\mathrm{mg} \mathrm{L}^{-1}\right)$ & \\
\hline 0,0 & $3,77 \mathrm{aB}$ & $7,00 \mathrm{aA}$ & $5,61 \mathrm{aA}$ \\
0,5 & $2,00 \mathrm{~b} \mathrm{~A}$ & $2,08 \mathrm{~b} \mathrm{~A}$ & $3,00 \mathrm{~b} \mathrm{~A}$ \\
1,5 & $0,96 \mathrm{~b} \mathrm{~A}$ & $2,04 \mathrm{~b} \mathrm{~A}$ & $2,24 \mathrm{~b} \mathrm{~A}$ \\
\hline
\end{tabular}

${ }^{1}$ Médias seguidas por letras distintas, minúsculas na coluna e maiúsculas na linha dentro de BAP e dentro de ANA, diferem entre si pelo teste de Tukey a 0,05 de significância.

TABELA 4. Comprimento médio (cm) de brotos de hortelã-pimenta em função das concentrações dos reguladores vegetais $\mathrm{BAP}, \mathrm{ANA}$ e $\mathrm{GA}_{3}$ combinados'

\begin{tabular}{llll}
\hline \multirow{2}{*}{$\mathbf{A N A}(\mathbf{m g ~ L}-1)$} & BAP $\mathbf{m g ~ L - 1})$ & \\
\cline { 2 - 4 } 0,0 & 0,0 & 2,0 & 4,0 \\
0,5 & $2,47 \mathrm{aA}$ & $0,74 \mathrm{aB}$ & $0,41 \mathrm{aB}$ \\
1,5 & $0,51 \mathrm{~b} \mathrm{~A}$ & $0,57 \mathrm{aA}$ & $0,36 \mathrm{aA}$ \\
\hline $\mathbf{G A}_{3}\left(\mathbf{m g ~ L}^{-1}\right)$ & $0,11 \mathrm{~b} \mathrm{~A}$ & $0,30 \mathrm{aA}$ & $0,25 \mathrm{aA}$ \\
\hline 0,0 & & $\mathrm{BAP}\left(\mathrm{mg} \mathrm{L}^{-1}\right)$ & \\
0,5 & $1,51 \mathrm{aA}$ & $0,53 \mathrm{aB}$ & $0,26 \mathrm{aB}$ \\
1,0 & $0,78 \mathrm{~b} \mathrm{~A}$ & $0,52 \mathrm{aA}$ & $0,41 \mathrm{aA}$ \\
\hline
\end{tabular}

${ }^{1}$ Médias seguidas por letras distintas, minúsculas na coluna e maiúsculas na linha dentro de ANA e dentro de $\mathrm{GA}_{3}$, diferem entre si pelo teste de Tukey a 0,05 de significância.

com reguladores vegetais (Tabela 4), resultado semelhante ao encontrado por Asmar et al. (2011). Possivelmente, a concentração endógena de fitohormônios da espécie estudada seja suficiente para estimular o crescimento dos brotos formados. Essa constatação ratifica a teoria de que a indução ou a inibição dos processos morfogenéticos in vitro dependem do balanço e da interação entre as substâncias de crescimento endógenas e exógenas (Monfort et al., 2012). Assim, sugere-se que após a multiplicação, os brotos de Mentha $x$ Piperita sejam transferidos para meio de cultura sem reguladores vegetais, para promoção de seu crescimento.

Quanto à calogênese, os meios MS contendo BAP apresentaram maior percentual de formação de calos (Tabela 5). Provavelmente, este resultado foi observado devido às altas concentrações utilizadas, sugerindo que abaixo de 2 $\mathrm{mg} \mathrm{L}^{-1}$ de BAP este efeito talvez não fosse verificado. De maneira geral, concentrações elevadas de 
TABELA 5. Formação de calos (\%) em explantes de hortelã-pimenta em função das concentrações dos reguladores vegetais $\mathrm{BAP}, \mathrm{ANA}$ e $\mathrm{GA}_{3}$ combinados'.

\begin{tabular}{llll}
\hline & BAP $\left(\mathrm{mg} \mathrm{L}^{-1}\right)$ & & \\
\cline { 2 - 4 } ANA $\left(\mathrm{mg} \mathrm{L}^{-1}\right)$ & 0,0 & 2,0 & 4,0 \\
\hline 0,0 & $0,0 \mathrm{bB}$ & $89,58 \mathrm{aA}$ & $88,09 \mathrm{aA}$ \\
0,5 & $52,17 \mathrm{aB}$ & $64,58 \mathrm{~b} \mathrm{AB}$ & $79,17 \mathrm{aA}$ \\
1,5 & $33,33 \mathrm{aB}$ & $67,50 \mathrm{~b} \mathrm{~A}$ & $81,82 \mathrm{aA}$ \\
\hline $\mathrm{GA}_{3}\left(\mathrm{mg} \mathrm{L}^{-1}\right)$ & & $\mathrm{BAP}\left(\mathrm{mg} \mathrm{L}^{-1}\right)$ & \\
\hline 0,0 & $41,30 \mathrm{aB}$ & $54,17 \mathrm{~b} \mathrm{AB}$ & $71,43 \mathrm{aA}$ \\
0,5 & $14,58 \mathrm{bB}$ & $77,27 \mathrm{aA}$ & $87,50 \mathrm{aA}$ \\
1,0 & $29,17 \mathrm{ab} \mathrm{B}$ & $93,18 \mathrm{aA}$ & $88,64 \mathrm{aA}$ \\
\hline
\end{tabular}

'Médias seguidas por letras distintas, minúsculas na coluna e maiúsculas na linha dentro de ANA e dentro de $\mathrm{GA}_{3}$, diferem entre si pelo teste de Tukey a 0,05 de significância.

reguladores de crescimento vegetal favorecem a formação de calos (Bandeira et al., 2005).

Concluiu-se que o BAP favoreceu a sobrevivência de segmentos nodais de Mentha $x$ Piperita inoculados in vitro e, combinado ao $\mathrm{GA}_{3}$, a brotação dos explantes. Essas características, no entanto, não foram estimuladas pela adição de ANA ao meio de cultura. Após multiplicação dos brotos in vitro, estes devem ser transferidos para meio sem reguladores para seu desenvolvimento. Apesar dos efeitos benéficos do BAP na organogênese de $M$. $x$ Piperita, elevadas concentrações deste regulador de crescimento vegetal promoveram a formação de calos.

\section{REFERÊNCIA}

ASMAR, A.S. et al. Citocininas na multiplicação in vitro de hortelã-pimenta (Mentha piperita L.). Revista Brasileira de Plantas Medicinais, v.13,n.esp., p.533-38, 2011.

BANDEIRA, J.M. et al. Adequação de protocolo para micropropagação de Mentha viridis L.. In: CONGRESSO DE INICIAÇÃO CIENTÍFICA,14., ENCONTRO DE PÓS-GRADUAÇÃO, 7., 2005, Pelotas. Anais... Pelotas:Universidade Federal de Pelotas, 2005. CD-ROM.

BRUM, G.R.; SILVA, A.B.; PASQUAL, M. Efeito de diferentes concentrações de BAP e ANA na propagação in vitro da figueira (FicuscaricaL.). Ciência e Agrotecnologia, v.26, n.2, p.1403-9, 2002.

CALIXTO, J.B. Twenty-five years of research on medicinal plants in Latin America: a personal review. Journal of Ethnofarmacology, v.100, n.1-2, p.131-4, 2005.

CARDOSO, M.G. et al. Óleos essenciais. Lavras: UFLA, 2000. 42p.

CELLAROVA, E. Micropropagation of Mentha L.. In: BAJAJ, Y.P.S. (Ed.). Biotechnology in agriculture and forestry. v.19. Berlin, Heidelberg: Springer-Verlag, 1992. p.262-76.

CORREAA, A.D.; BATISTA, R.S.; QUINTAS, L.E.M. Plantas medicinais: do cultivo à terapêutica. 6.ed. Petrópolis: Bozes, 2003. 247p.

GARLET, T.M.B. et al. Influência de citocininas na micropropagação de Menthax gracilis Sole. Revista Brasileira de Plantas Medicinais, v.13, n.1, p.30-4, 2011.

GHANTI, K. et al. Rapid regeneration of Mentha piperita L. from shoot tip and nodal explants. Indian Journal of Biotechnology, v.3, n.4, p.594-8, 2004.

GOLENIOWSKI, M.E.;FLAMARIQUE, C.; BIMA, P. Micropropagation of oregano (Origanumvulgare $\mathrm{x}$ applii) from meristem tips. In Vitro Cellular \& Developmental Biology, v.39, n.2, p.125-8, 2003.

HÉCTOR, E. et al. Un método para la desinfección y el establecimiento in vitro de la menta japonesa (Mentha arvensis L.). Cultivos Tropicales, v.26, n.1, p.69-71, 2005.

LIMA, C.S.M. et al. Influência de fitorreguladores no crescimento in vitro de partes aérea de Mentha viridis. Revista Brasileira de Biociências, v.5, supl.2, p.66971, 2007.

LIN, M.; STABA, E.J. Peppermint and spearmint tissue cultures, callus formation and submerged culture. Lloydia, v.24, p.139-45, 1961.

LORENZI, H.; MATOS, F.J.A. Plantas medicinais no Brasil: nativas e exóticas. 2.ed. Nova Odessa: Instituto Plantarum, 2008. 544p.

LUCCHESINI, M. et al. Optimisation of in vitro cultural conditions of some officinal species. Acta Horticulturae, v.1, n.723, p.303-8, 2006.

MONFORT, L.E.F. et al. Efeito do BAP no cultivo in vitro de Ocimum selloi Benth. Revista Brasileira de Plantas Medicinais, v.14, n.3, p.458-63, 2012.

MORGANTE, C.V.; LOMBARDI, S.P. Hormônios vegetais e biotecnologia. Piracicaba: Esalq, 2004. 13p.

MURASHIGE, T.; SKOOG, F. A revised medium for rapid growth and bioassay with tobacco tissue cultures. Physiology Plantarum, v.15, n.3, p.473-97, 1962.

PASQUAL, M. Textos acadêmicos: meios de cultura. Lavras: FAEPE/UFLA, 2001. 127p.

RAJA, H.D.; AROCKIASAMY, D.I. In vitro propagation of Mentha viridis L. from nodal and shoot tip explants. Plant Tissue Culture and Biotechnology, v.18, n.1, p.1-6, 2008.

SHASANY, A.K. et al. High regenerative nature of Mentha arvensis internodes. Journal of Biosciences, v.23, n.5, p.641-6, 1998.

SKALA, E.; WYSOKINSKA, H. In vitro regeneration of Salvia nemorosa L., from shoot tips and leaf explants. In Vitro Cellular \& Developmental Biology - Plant,

Rev. Bras. PI. Med., Campinas, v.16, n.2, supl. I, p.350-355, 2014. 
v.40, p.596-692, 2004.

SOUZA, C.R. et al. Influência do ácido giberélico sobre a arquitetura de plantas de feijão no início de desenvolvimento. Acta Scientiarum Agronomy, v.32, n.2, p.325-32, 2010.

SOUZA, M.A.A. Produção de biomassa e rendimento de óleos essenciais de plantas de hortelã (Mentha piperita) em cultivo hidropônico com diferentes concentrações de nitrogênio e fósforo. 2006. 87p. Dissertação (Mestrado - Área de Concentração em Agronomia) - Universidade Federal Rural do Rio de Janeiro, Seropédica.

SUNANDAKUMARI, C. et al. Rapid axillary bud proliferation and ex vitro rooting of herbal spice, Mentha piperita L..
Indian Journal of Biotechnology, v.3, n.1, p.108-12, 2004.

VEIGA-JUNIOR, V.F.; MELLO, J.C.P. As monografias sobre plantas medicinais. Revista Brasileira de Farmacognosia, v.18, n.3, p.464-71, 2008.

VIEIRA, M.L.C. Conservação de germoplasma in vitro. Disponível em: <http://www.biotecnologia.com.br/ revista/bio14/conserva.pdf>. Acesso em: 11 ago. 2009.

WEISS, D.; ORI, N. Mechanisms of cross talk between gibberellin and other hormones. Plant Physiology, v.144, n.3, p.1240-6, 2007.

WHO - WORLD HEALTH ORGANIZATION. WHO monographs on selected medicinal plants.v.4. Spain: WHO, 2009. 456p. 